\title{
You are What Your Children Eat: Using Projective Techniques to Investigate Parents' Perceptions of the Food Choices Parents Make for Their Children
}

\author{
S.C. Jones, ${ }^{*}$ D. McVie and G. Noble
}

Centre for Health Initiatives, University of Wollongong, Australia

\begin{abstract}
The aim of this study was to investigate the underlying reasons for parents' decisions about their children's diets. This study used the projective methodologies of picture response and third-person techniques (projective questioning), which are designed to elicit people's underlying motivations, beliefs, attitudes and concerns, particularly those beliefs which people find hard to articulate. We found a significant difference in parents' perceptions of the woman in the scenario in response to all four of the statements that related directly to food choices. This study provides support for the contention that parents reports of their intentions and behaviours regarding food choices for their children are associated with their perceptions of value judgments associated with these behaviours. It appears the use of projective methodologies have promise as tools for investigating subconscious, or at least not readily communicated, reasons for parents' food choices for their children.
\end{abstract}

Keywords: Projective techniques, parents, nutrition education, food choices.

\section{INTRODUCTION}

\section{The Context: Children's Food Consumption}

The worldwide prevalence of obesity is increasing in children (Reilly, 2005), and there is evidence that overweight children are far more likely to become obese as adults (Wright, Parker, Lamont, \& Craft, 2001). The prevalence of childhood overweight and obesity in Australia is high by international standards, and it is estimated that one in four Australian children are overweight or obese (Booth, Wake, Armstrong, Chey, Hesketh, \& Mathur, 2001). While overweight and obesity is a result of a complex interaction of a number of factors (Green \& Reese, 2006), poor eating habits are acknowledged as a significant contributing factor.

Research shows that the majority of children consume insufficient amounts of fruit, vegetables and dietary fiber (Hampl, Taylor, \& Johnston, 1999), and that the most commonly eaten foods are fruit drink, carbonated beverages, milk, and French fries (Skinner, Betty, Houck, Bounds, Morris, Cox, Moran, \& Coletta, 1999). Recent research confirms that children are eating outside the home more regularly, eating larger portion sizes, consuming more soft drinks, and eating less fruit and vegetables (Fitzgibbon \& Stolley, 2006).

A variety of factors have been reported as influencing food choice, including physiological, psychological, social, environmental, and cultural factors. Researchers have attempted to develop conceptual models to predict individuals' food choices. While these models are limited in their capacity to predict food choice they demonstrate the complexity of these decisions (Furst, Connors, Bisogni, Sobal, \& WinterFalk, 1996; Wetter, Goldberg, King, Sigman-Grant, Baer,

*Address correspondence to this author at the Centre for Health Initiatives, University of Wollongong, Australia; Tel: +61 24221 5106; Fax: +61 24221 3370: E-mail: sandraj@uow.edu.au
Crayton, Devine, Drewnowski, Dunn, Johnson, Pronk, Saelens, Synder, Walsh, \& Warland, 2001).

Television advertising of foods aimed at children has been argued to be an important factor in children's eating patterns and, in turn, in the rising levels of childhood obesity. Repeated studies across different countries have demonstrated that food advertisements are inconsistent with dietary guidelines (Story \& Faulkner, 1990; Taras \& Gage, 1995). However, there is limited evidence of a direct link between food ads aimed at children and children's eating patterns (Ofcom, 2004), primarily because while food preferences may be influenced by child-targeted advertising, food purchase decisions are generally made by parents.

A review of the published literature (Campbell \& Crawford, 2001) concluded that children's eating behaviours are strongly influenced by the family food environment. Factors that were found to be important in the family food environment were: parental food preferences and beliefs, children's food exposure, role modeling, media exposure and parentchild interactions surrounding food. Aside from media exposure (discussed above) these influences can be grouped as direct and indirect influences.

Direct influences: It is widely agreed that there is an element of control in parent-child interactions surrounding food. This can be broadly categorised as: controls over food (e.g., restrictions on intake of unhealthy foods); and controls using food (i.e., providing or restricting foods as reward and punishment).

Indirect influences: Parental attitudes influence children's nutrition, particularly young children's nutrition, through exposure to different types of foods and to parental food habits and preferences (Wardle, 1995). Parental food choice has been reported to be influenced by a number of factors such as mothers' beliefs about the healthfulness of foods (Contento, Basch, Shea, Gutin, Zybert, Michela, \& 
Rips, 1993), own consumption practices (Vereecken, Keukelier, \& Maes, 2004), perceived environmental and social barriers (Hart, Bishop, \& Truby, 2002), social class (Hupkens, Knibbe, Otterloo, \& Drop, 1998) and nutrition knowledge (Variyam, Blaylock, Lin, Ralston, \& Smallwood, 1999).

Thus it is not surprising that studies find a correlation between mothers' and children's food intakes (Olivera, Ellison, Moore, Gillman, Garrahie, \& Singer, 1992). A study of children aged 9 to 13 years and their parents ( $n=112$ pairs) found a strong association between the parent's and child's snack food intake, motivations and levels of body dissatisfaction (Brown \& Ogden, 2004); and correlations have also been found between mothers' dieting beliefs and behaviours and the diet-related beliefs of their 5-year-old daughters (Abramovitz \& Birch, 2000).

Other studies have shown a relationship between mothers' health motivation and children's diets (Contento et al., 1993), although the nature of this relationship has been called into question by a UK study of 211 mothers and female carers of primary school children (St John Alderson \& Ogden, 1999). While these mothers reported that their choices of foods for their children were motivated by their concerns for long-term health value and nutritional value and that they were more motivated by health considerations when choosing food for their children than for themselves, their food records showed that they actually fed their children more unhealthy foods and less healthy foods than they fed themselves. The authors suggested that one reason for the apparently contradictory results may be that the mothers' responses to the motivations section of the questionnaires reflected what they thought their motivations should be. Further, as Michael Young highlighted in an interview about the process of researching his book Family and Kinship in East London, food has important emotional and social associations for people (Thompson, 2004), this the 'meaning' of food and food choices goes beyond nutritional benefits. This highlights the need for different research techniques designed to counter such biases if we are to begin to understand the underlying reasons for parents' decisions about their children's food.

\section{Projective Techniques Research}

The traditional approach to improving children's diets has been to educate parents about the importance of healthy food choices. However, there is considerable evidence that the majority of parents know, at least at a basic level, which foods are 'good' or 'bad' for their children (Variyam et al., 1999). So, the question remains: what factors motivate the food decisions parents make for their children? Recognising that direct questioning will not provide the answer to this question, the current study used an indirect measure to investigate the underlying reasons for parents' decisions about their children's diets.

The study reported in this paper used the projective methodologies of picture response and third-person techniques (projective questioning), which are designed to elicit people's underlying motivations, beliefs, attitudes and concerns (Kassarjan, 1974), particularly those beliefs which people find hard to articulate. It has long been known that people automatically infer the personality traits of other peo- ple and attribute agentic motives to their behaviour (Heider, 1944; Kelley, 1973).

Mason Haire's 'shopping list' study (Haire, 1950) is one of the earliest and best-known examples of implicit personality rating methodology in marketing research (the technique of 'other's personality' ratings). Haire conducted 100 interviews with women in the Boston area; each housewife was given a shopping list and asked to describe the owner of the list (one version included 'Nescafé Instant Coffee' and the other 'Maxwell House Coffee (Drip Grind)'. Haire hypothesised that the reasons for women's decisions not to purchase instant coffee went far beyond perceived taste (the reason generally given in response to direct questioning) and primarily reflected negative perceptions of the 'type of people' who use the product. The participants' open-ended responses were analysed and strictly coded word by word. Several significant differences were found between the two groups: specifically, the Nescafe instant coffee purchasers were more frequently described as 'lazy', 'poor planners', 'spendthrifts' and 'bad wives;' whereas the Maxwell House regular coffee purchasers were more often described as 'thrifty' and 'good wives'.

Two decades later (Webster \& Von Pechmann, 1970) replicated the Haire study, hypothesising that increasing acceptance of instant coffee in the US would result in a reduction if not elimination of the negative traits assigned to users of the product. The Webster and Von Pechmann study largely duplicated Haire's 'shopping list' methodology and, as the investigators had hypothesised, no significant differences were found between the characteristics ascribed to the two hypothetical shoppers. The study was replicated in the early 1970s in Canada (Lane \& Watson, 1975) and Norway (Arndt, 1973).

These techniques have more recently been successfully used, for example, to investigate fear of flying (Adams, 1997), to elicit underlying reasons for non-purchase of dry soup mixes (Maholtra, Hall, Shaw, \& Oppenheim, 2002), and to examine personality characteristics associated with alcohol consumption (Jones \& Rossiter, 2003).

We believe that these methodologies have been underutilised in health research. The few studies in this area that have utilised projective methodologies have demonstrated their potential to add greatly to our understanding of people's decisions regarding social and health-related behaviours, such as food choice, although these have tended to focus on time- and resource-intensive techniques such as having participants draw or paint pictures or develop materials for 'other' people. For example, a Dutch study utilising women's own drawings provided an insight into their affective and cognitive associations between food and pleasure, health and socialisation (Sijtsema, Linnemann, Backus, Jongen, van Gaasbeek, \& Dagevos, 2007); a US study utilising visual images provided insight into African Americans' perceptions regarding colorectal cancer screening (Wiehagen, Caito, Thompson, Casey, Weaver, Jupka, \& Kreuter, 2007); and a study with learning disabled children incorporating sentence completion exercises, written prompts and drawings, photographs, feelings cards, and 'wishes' increased children's capacity to answer questions and engage actively in the research process (Kelly, 2007). The use of a visual or verbal scenario (such as in the 'shopping list' studies), with 
an associated questionnaire to measure respondent perceptions, has the potential to be used to investigate the values and attitudes of larger groups of people in a time- and resource-efficient manner.

\section{METHODS}

Ethics approval for conduct of the study was obtained from the University's Human Research Ethics Committee.

In order to test the methodology and the data collection instruments, a pilot study was conducted with 27 parents at a university child-care centre. This enabled us to test the methodology, stimuli, and data collection instruments. Minor modifications were subseqeuntly made to the structure of the questionnaires and the wording of several items, based on the feedback from the pilot study.

\section{Survey Instruments}

The survey instrument was designed to gain an understanding of the factors that motivate the food decisions parents make for their children. While several scales were identified that measure general parenting styles and attitudes (Sessa, Avenevoli, Steinberg, \& Morris, 2001), family functioning (Renck Jalongo \& Isenberg, 2004), and family effectiveness (Barbour \& Barbour, 1997), none specifically evaluated parenting in the context of food choice behaviours. As such, the investigators developed questions through an iterative process based on a review of the literature and the results of a focus group discussion with six mothers of preschool aged children about general qualities of 'good' and 'bad' parents and the food-related behaviours of each type of parent.

The resultant measure was a series of eight statements about a woman in a scenario (illustrated by a photograph or story). The statements were - The mother is:

- spending quality time with her children

- educating her children about boundaries

- being her children's friend as well as a being their parent

- making sure that her children are having fun

- providing her children with healthy food

- exposing her children to a variety of food

- educating her children about food and nutrition; and

- controlling her children's weight

For each question, respondents were asked to indicate on a 5-point Likert scale (from $1=$ 'strongly disagree' to $5=$ 'strongly agree') the extent to which they agreed with each statement. The questionnaire also allowed for a 'don't know' response.

Four different scenarios (two picture scenarios and two written scenarios) were developed to precede the questions but all other aspects of the questionnaires were identical.

In the picture scenarios, participants were given a photograph of a mother shopping for after-school snacks with her children. Photographs were taken by one of the investigators in a local supermarket. In the 'healthy' photo condition the family was in the fruit and vegetable section of the super- market purchasing carrots and apples and had a bottle of milk in the shopping cart. In the 'unhealthy' photo condition the family was in the confectionery aisle purchasing chocolate bars and had a bottle of cordial in the shopping cart.
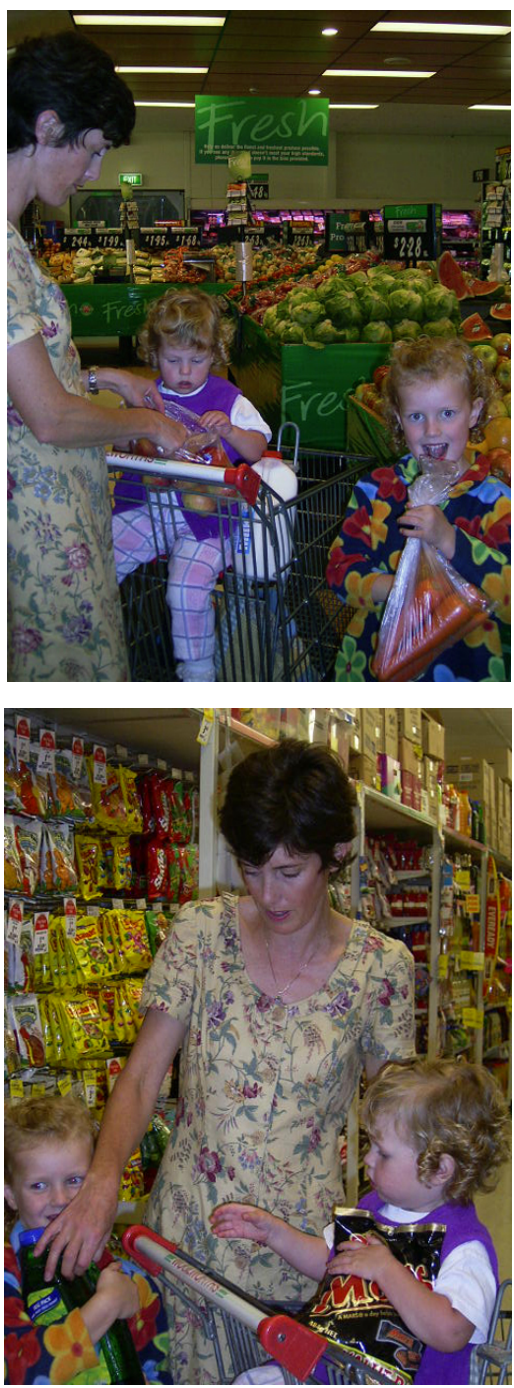

In the written scenarios, participants were presented with a 'story' about a mother and her two children. Both stories were identical except for the food the mother purchased for the children's snack or afternoon tea.

"Naomi is 35 years old. She has two children, Emily aged 5 and Lucy aged 3. On Tuesday afternoon Naomi finished work and picked up Emily from school (kindergarten) and Lucy from pre-school at $3 \mathrm{pm}$. She took them to the supermarket and bought Emily and Lucy (an apple, carrot and milk / a Mars Bar and Pop Top each) to snack on, then they went to the park to play on the swings and feed the ducks. At $5 \mathrm{pm}$ she drove them home, and they all watched a Disney video together before dinner. At 7.00 pm, Naomi gave Emily and Lucy a bath, and read them a story in bed."

\section{The Study}

Pre-school aged children (3- to 5-year-olds) were chosen as the focus of this research because parents of children in this age group are responsible for the majority of food decisions made for their children. To broaden the range of re- 
spondents, the main study was conducted across 6 child-care centers in the Illawarra region. Permission for the study was obtained from KU Children Services and the Directors of the individual centres that were invited to participate.

Parents attending the centres were invited by a research assistant to participate in the survey during a 2-week period in October 2004. The research assistant was present at the main access door of the centre during the peak drop-off time (8.00 am to $9.00 \mathrm{am}$ ). Those parents agreeing to participate were randomly assigned one of the four conditions and were given a questionnaire which they were asked to complete at home and return to the centre in an unmarked sealed envelope. Participants were also given a separate consent form and return envelope, and were provided with a $\$ 10$ book voucher for returning their completed survey and consent form. Written consent was obtained from the Director of the child care center and all participants.

In total, 120 surveys were distributed to parents during a 2-week period in October 2004, and 87 parents completed and returned the survey, a return rate of $72.5 \%$.

\section{RESULTS}

The mean age of respondents was 35.7 years (range 23 to 64 years, SD 6.4 years); $88.5 \%$ (77) of the respondents were female. Eighty per cent of the respondents had completed a post-secondary qualification: $46 \%$ (40) had completed a graduate or postgraduate university degree or diploma and $31 \%$ (27) had completed a TAFE certificate or diploma. All but two of the respondents $(97.7 \%)$ reported that English was the primary language spoken at home. All respondents had at least one child under the age of 6 .

The number of participants was relatively even across the scenarios (healthy written $=20$, unhealthy written $=21$, healthy photo $=26$, and unhealthy photo $=20$ ), and there were no significant differences between the four groups on any of the demographic variables (e.g., average age, number of children, or education level).

\section{'Healthy' versus 'unhealthy' conditions.}

For consistency with the pilot study, we first compared the two 'healthy' conditions (healthy photo and healthy scenario) to the two 'unhealthy' conditions (unhealthy photo and unhealthy scenario). The results are provided in Table $\mathbf{1}$, and discussed below.
There were significant differences between the respondents' perceptions of whether the mother was spending quality time with her children in the 'healthy' and 'unhealthy' conditions, with proportionally more respondents agreeing with this statement in relation to the healthy scenario $(69.6 \%$ versus $53.7 \%, \mathrm{p}=0.3)$. There was an even greater difference, $63 \%$ with the healthy scenario compared to only $4.9 \%$ with the unhealthy scenario, in the proportion who agreed that the mother was 'exposing her children to a variety of food' $(\mathrm{p}=.000)$; and a similar difference, $63 \%$ compared to $9.8 \%$, in the proportion who agreed with the statement that the mother was 'educating her children about food and nutrition' $(p=000)$. Almost all respondents $(95.7 \%)$ for the healthy scenario, compared with none for the unhealthy scenario, agreed the mother was 'providing her children with healthy food' ( $p=.000$ ); and $28.3 \%$ of respondents for the healthy scenario, compared to $7.3 \%$ for the unhealthy scenario, agreed the mother was 'controlling her children's weight' $(\mathrm{p}=.008)$.

However, there were no significant differences between respondents' perceptions of what was happening in the 'healthy' and 'unhealthy' conditions in relation to the mother educating her children about boundaries (mean score 3.5 vs. 3.1 ); making sure that her children were having fun (mean score 3.8 vs. 3.6); or being her children's friend as well as being their parent (3.9 vs. 3.5).

\section{'Healthy' Versus 'Unhealthy' Conditions by Scenario Type}

The results were then analysed by scenario type (that is, separately for the photo scenarios and the written scenarios) to see whether there were differences in the responses as a result of the specific method used. The results are discussed below.

Photo scenarios: The results for the photo scenarios showed the same pattern of effects as that for the photo and written scenarios combined. That is, there were statistically significant differences between the healthy photo and unhealthy photo conditions for perceptions that the mother was spending quality time with her children (mean score 3.3 vs. $2.8, \mathrm{t}=1.73, \mathrm{p}=.09)$; providing her children with healthy food (mean score 4.2 vs. $1.7, \mathrm{t}=14.42, \mathrm{p}=.000$ ); exposing her children to a variety of food (mean score 3.9 vs. $1.8, \mathrm{t}=$ $6.38, \mathrm{p}=.000$ ); educating her children about food and nutri-

Table I. Mean Ratings of the Mother in "Healthy" Versus "Unhealthy" Scenarios

\begin{tabular}{|c|c|c|c|c|}
\hline & Healthy Photo/ Scenario $(n=46)$ & Unhealthy Photo/ Scenario $(n=41)$ & $\mathbf{t}$ & Sig \\
\hline Quality time & 3.83 & 3.34 & 2.04 & .03 \\
\hline Being friend & 3.87 & 3.54 & 1.38 & .12 \\
\hline Have fun & 3.80 & 3.63 & .88 & .28 \\
\hline Variety & 4.09 & 2.37 & 5.58 & .000 \\
\hline Educating & 3.83 & 2.56 & 4.70 & .000 \\
\hline Control weight & 3.54 & 2.73 & 2.83 & .008 \\
\hline
\end{tabular}


tion (mean score 4.0 vs. $2.8, \mathrm{t}=2.77, \mathrm{p}=.01$ ); and controlling her children's weight (mean score 3.5 vs. $2.6, t=2.58, \mathrm{p}$ $=.01)$.

Written scenarios: The results for the written scenarios showed the same pattern of effects as that for the photo and written scenarios combined, except for one item. There were statistically significant differences between the healthy written and unhealthy written scenarios for perceptions that the mother was: spending quality time with her children (mean score 4.5 vs. $3.9, \mathrm{t}=2.29, \mathrm{p}=.03$ ); providing her children with healthy food (mean score 4.1 vs. $2.2, t=6.20, p=.000)$; exposing her children to a variety of food (mean score 4.3 vs. $2.9, \mathrm{t}=2.79, \mathrm{p}=.008$ ); educating her children about food and nutrition (mean score 3.7 vs. 2.3, $\mathrm{t}=3.68, \mathrm{p}=.001$ ). However, the results for perceptions that the mother was controlling her children's weight were not statistically significant, although the mean scores differed in the expected direction (mean score 3.6 vs. 2.9, ns).

Differences between scenario types: Finally, the data were analysed by scenario type - within healthiness conditions - to determine whether there were differences in responses between the photographic and written scenarios.

The only items for which there was a significant difference between the scenario types (within the condition) were the perceptions that the mother was spending quality time with her children and that she was having fun with her children. In relation to quality time, across both conditions the rating was significantly lower in the photo scenario than in the written ( 3.1 vs. $4.5, \mathrm{t}=-5.16, \mathrm{p}=.000$ in the healthy scenarios; and 2.8 vs. $3.9, \mathrm{t}=-3.06, \mathrm{p}=.004$ in the unhealthy scenarios). For the item about having fun, across both conditions the rating was also significantly lower in the photo scenario (3.6 vs. $4.1, \mathrm{t}=-2.48, \mathrm{p}=.02$; and 3.3 vs. $4.0, \mathrm{t}=-2.16$, $\mathrm{p}=.04)$.

\section{DISCUSSION}

A large proportion of Australian children are overweight or obese and this is primarily attributed to lack of physical activity and poor dietary choices. While a variety of factors have been found to influence food choice, children's eating behaviours are strongly influenced by the family food environment and particularly by parents' direct (control-related) and indirect (modelling and attitudinal) actions.

There is considerable evidence that most parents have a reasonable understanding of which foods are beneficial and which foods are deleterious to their children's health (Variyam et al., 1999). Parents consistently report being concerned about their children's diet (Contento et al., 1993) and claim that the food choices they offer their children reflect these concerns; however, studies have shown that they feed their children a less healthy diet than that they consume themselves (St John Alderson \& Ogden, 1999). The available evidence suggests that in many families there is a discrepancy between the stated attitudes and behaviours of parents and the actual food provided to the children.

The study reported in this paper used a projective methodology to examine the inferences parents make about other parents' food choices for their children to investigate underlying reasons for such choices. The results - in terms of people's willingness to make judgments about an individual and her motives based on extremely limited information - are consistent with previous studies. As described above, Mason Haire found that "housewives" decisions not to purchase instant coffee went far beyond perceived taste (the reason generally given in response to direct questioning) and primarily reflected negative perceptions of the 'type of people' who use the product; the study also found that these perceptions could be accessed simply by asking women to describe the owner of a hypothetical shopping list (Haire, 1950). A more recent study of perceptions of personality characteristics associated with consumption of alcohol found that in the minds of Australian young adults, certain positive personality characteristics were associated with the use of alcohol (in particular, young women who drink are perceived reliably as more 'interesting' and 'self-assured' than young women who don't drink) and that respondents perceived themselves as able to assess an individual's personality on the basis of a 6or 7-line shopping list (Jones \& Rossiter, 2003).

In this study, we found a significant difference in parents' perceptions of the woman in the scenario in response to all four of the statements that related directly to food choices. That is, parents who viewed the healthy (photo or written) scenario rated the mother more favourably in response to the items: 'providing her children with healthy food', 'exposing her children to a variety of foods', 'educating her children about food and nutrition', and 'controlling her children's weight'. As previously discussed, only two of these could be said to be objectively related to the information in the scenario but the differences in ratings between the scenarios were of similar magnitude for each of the four items. There was also a significant difference regarding the statement 'spending quality time with her children', with a higher level of agreement among those exposed to the 'healthy' scenario.

This study provides support for the contention that parents report such intentions and behaviours due, in part, to their perceptions of the value judgments that are associated with these behaviours.

There is a need for further studies to investigate parents' perceptions of motivations for food choices - both their own and those of other parents - and the use of projective methodologies such as those employed in the current study appear to have promise for such investigations.

\section{REFERENCES}

Abramovitz, B. A., \& Birch, L. L. (2000). Five-years-old girl's ideas about dieting are predicted by their mother's dieting. Journal of the American Dietetic Association, 100(10), 1157-1163

Adams, M. (1997). White knuckles, knocking knees. Sales \& Marketing Management, 149, 94

Arndt, J. (1973). Haire's shopping list revisited. Journal of Advertising Research, 13(5), 57-61

Barbour, C., \& Barbour, N. H. (1997). Families, Schools and Communities, Building Partnerships for Educating Children: Merrill: New Jersey.

Booth, M. L., Wake, M., Armstrong, T., Chey, T., Hesketh, K., \& Mathur, S. (2001). The epidemiology of overweight and obesity among Australian children and adolescents. Australian and New Zealand Journal of Public Health, 25, 162-169

Brown, R., \& Ogden, J. (2004). Children's eating attitudes and behaviour: A study of the modelling and control theories of parental influence. Health Education Research, 19(3), 261-271

Campbell, K., \& Crawford, D. (2001). Family food environments as determinants of preschool-aged children's eating behaviours: Implica- 
tions for obesity prevention policy. A review. Australian Journal of Nutrition and Dietetics, 58, 19-25

Contento, I. R., Basch, C., Shea, S., Gutin, B., Zybert, P., Michela, J. L., \& Rips, J. (1993). Relationship of mothers' food choice criteria to food intake of preschool children: Identification of family subgroups. Health Education Quarterly, 20, 243-259

Fitzgibbon, M. L., \& Stolley, M. (2006). Promoting health in an unhealthful environment: Lifestyle challenges for children and adolescents. Journal of the American Dietetics Association, 106(4), 518-522

Furst, T., Connors, M., Bisogni, C., Sobal, J., \& Winter-Falk, L. (1996). Food choice: a conceptual model of the process. Appetite, 26, 247266

Green, G., \& Reese, S. A. (2006). Childhood obesity: A growing phenomenon for physical educators. Education, 127(1), 121-124

Haire, M. (1950). Projective techniques in marketing research. Journal of Marketing, 14, 649-656

Hampl, J. S., Taylor, C. A., \& Johnston, C. S. (1999). Intakes of vitamin C, vegetables and fruits: Which schoolchildren are at risk? Journal of American College Nutrition, 18, 582-590

Hart, K. H., Bishop, J. A., \& Truby, H. (2002). An investigation into school children's knowledge and awareness of food and nutrition. Journal of Human Nutrition \& Dietetics, 15, 129-140

Heider, F. (1944). Social perception and phenomenal causality. Psychological Review, 51, 358-374

Hupkens, C. L. H., Knibbe, R. A., Otterloo, A. H. V., \& Drop, M. J. (1998). Class differences in the food rules mothers impose on their children: A cross-national study. Social Science and Medicine, 47(9), 1331-1339

Jones, S. C., \& Rossiter, J. R. (2003). Personality characteristics ascribed to young women who drink alcohol. Drug and Alcohol Review, 22(2), $117-124$

Kassarjan, H. H. (1974). Projective methods. In R. Ferber (Ed.), Handbook of Marketing Research. New York: McGraw-Hill.

Kelley, H. H. (1973). The process of causal attribution. American Psychologist, 28, 107-113

Kelly, B. (2007). Methodological Issues for Qualitative Research with Learning Disabled Children. International Journal of Social Research Methodology, 10(1), 21-35

Lane, G. S., \& Watson, G. L. (1975). A Canadian replication of Mason Haire's 'shopping list' study. Journal of the Academy of Marketing Science, 3(1), 48-59

Maholtra, N., Hall, J., Shaw, M., \& Oppenheim, P. (2002). Marketing Research: An Applied Orientation. French's Forest: Pearson Education.

Ofcom. (2004). Childhood obesity - food advertising in context. Children's food choices, parents' understanding and influence, and the role of food promotion. London: UK Office of Communication.

Olivera, S. A., Ellison, R. C., Moore, L. L., Gillman, M. W., Garrahie, E. J., \& Singer, M. R. (1992). Parent-child relationships in nutrient in- take: The Framingham Children's Study. American Journal of Clinical Nutrition, 56, 593-598

Reilly, J. (2005). Descriptive epidemiology and health consequences of childhood obesity. Best Practice \& Research in Clinical Endocrinology \& Metabolism, 19(3), 327-341

Renck Jalongo, M., \& Isenberg, J. P. (2004). Exploring Your Role: A Practitioner's Introduction to Early Childhood Education. New Jersey: Merrill Prentice Hall.

Sessa, F. M., Avenevoli, S., Steinberg, L., \& Morris, A. S. (2001). Correspondence among informants on parenting: Preschool children, mothers and observers. Journal of Family Psychology, 15(1), 53-68

Sijtsema, S., Linnemann, A., Backus, G., Jongen, W., van Gaasbeek, T., \& Dagevos, H. (2007). Exploration of projective techniques to unravel health perception. British Food Journal, 109(6), 443-456

Skinner, J. D., Betty, R. C., Houck, K. S., Bounds, W., Morris, M., Cox, D. R., Moran, J., \& Coletta, F. (1999). Longitudinal study of nutrient and food intakes of white preschool children aged 24 to 60 months. Journal of the American Dietetic Association, 99, 1514-1521

St John Alderson, T., \& Ogden, J. (1999). What do mothers feed their children and why? Health Education Research, 14, 717-727

Story, M., \& Faulkner, P. (1990). The prime time diet: A content analysis of eating behaviour and food messages in television program content and commercials. American Journal of Public Health, 80, 738-740

Taras, H. L., \& Gage, M. (1995). Advertised foods on children's television. Archives of Pediatric and Adolescent Medicine, 149, 649-652

Thompson, P. (2004). Reflections on researching Family and Kinship in East London (Interview with Michael Young). International Journal of Social Research Methodology, 7(1), 35-44

Variyam, J., Blaylock, J., Lin, B., Ralston, K., \& Smallwood, D. (1999). Mother's nutrition knowledge and children's dietary intakes. American Journal of Agricultural Economics, 81, 373-384

Vereecken, C. A., Keukelier, E., \& Maes, L. (2004). Influence of mother's educational level on food parenting practices and food habits of young children. Appetite, 43, 93-103

Wardle, J. (1995). Parental influences on children's diets. Proceedings of the Nutrition Society, 54, 747-758

Webster, F. E., \& Von Pechmann, F. (1970). A replication of the 'shopping list' study. Journal of Marketing, 34, 61-77

Wetter, A., Goldberg, J., King, A., Sigman-Grant, M., Baer, R., Crayton, E., Devine, C., Drewnowski, A., Dunn, A., Johnson, G., Pronk, N., Saelens, B., Synder, D., Walsh, K., \& Warland, R. (2001). How and why do individuals make food and physical activity choices? Nutritional Reviews, 59, S11-S20

Wiehagen, T., Caito, N. M., Thompson, V. S., Casey, C. M., Weaver, N. L., Jupka, K., \& Kreuter, M.W. (2007). Applying projective techniques to formative research in health communication development. Health Promotion Practice, 8(2), 164-172

Wright, C. M., Parker, L., Lamont, D., \& Craft, A. W. (2001). Implications of childhood obesity for adult health: findings from the thousand families cohort study. British Medical Journal, 323, 1280-1284 